\title{
PERTUMBUHAN TANAMAN JATI (Tectona grandis L.f) DARI BERBAGAI RAS LAHAN DI PULAU MUNA
}

\author{
Growth of Teak (Tectona grandis L.f) Originated from Various Land Race in Muna Island \\ Bintarto Wahyu Wardani dan/and Budi Santoso \\ Balai Penelitian Kehutanan Makassar \\ Jl. Perintis Kemerdekaan Km 6, Makassar, Telp. (0411) 554049
}

Naskah masuk : 11 Februari 2008 ; Naskah diterima : 4 Februari 2009

\begin{abstract}
Land race trial of teak species was carried out in Tampo, Muna Island, South East Sulawesi Province to assess the suitability of the land race on teak at eighteen months old. A Randomized Complete Block Design using 25 tree plots with 6 blocks as replications and 7 land races as treatments were used. The site of study is located at altitude about 5 - $10 \mathrm{~m}$ above sea level, with average temperature $25^{\circ} \mathrm{C}$ to $27{ }^{\circ} \mathrm{C}$ and rainfall of $1,800 \mathrm{~mm}$ per year. The results showed that treatment had a highly significant effect on survival rate (49.33 - $82.67 \%$ ), but no significant effect was indicated in growth of height and diameter. Bonea land race showed highest growth $(118.23 \mathrm{~cm})$ and diameter $(20.08 \mathrm{~mm})$.
\end{abstract}

Keywords: land race trial, Tectona grandis L.f, and Muna Island

\begin{abstract}
ABSTRAK
Uji ras lahan tanaman jati dilakukan di Tampo, Pulau Muna, Propinsi Sulawesi Tenggara. Penelitian ini menggunakan Rancangan Acak Lengkap Berblok, dengan 7 ras lahan, 6 blok dan 25 tree plot pada setiap blok, tanaman berumur 18 bulan. Lokasi penelitian berada pada ketinggian $5-10 \mathrm{~m}$ dpl, suhu rata-rata $25-27^{\circ} \mathrm{C}$ dengan curah hujan tahunan $1.800 \mathrm{~mm}$. Hasil penelitian ini menunjukkan rata-rata persen hidup berbeda sangat nyata, rata-rata persen hidup mencapai 49,33 - 82,67\%, persen hidup tertinggi ditunjukkan oleh ras lahan Tampo (82,67\%). Pertumbuhan tinggi dan diameter tanaman umur 18 bulan tidak berbeda nyata. Pertumbuhan tertinggi $(118,23 \mathrm{~cm})$ dan diameter terbesar $(20,08 \mathrm{~mm})$ dicapai ras lahan Bonea.
\end{abstract}

Kata Kunci : uji ras lahan, Tectona grandis L.f, dan Pulau Muna

\section{PENDAHULUAN}

\section{A. Latar Belakang}

Jati (Tectona grandis L.f) merupakan jenis kayu mewah dan tergolong memiliki keawetan dan kekuatan kayu kelas kedua. Sifat fisik kayu jati mempunyai kelebihan dibandingkan dengan jenis kayu yang lainnya, sehingga kayu jati dapat digunakan untuk berbagai penggunaan seperti peralatan rumah tangga, komponen bangunan, konstruksi berat, galangan kapal dan lain-lain. Kayu jati saat ini harganya semakin tinggi, sehingga penggunaannya bukan hanya untuk konstruksi berat, tetapi cenderung lebih banyak digunakan untuk mebel, finir sayatan yang ditempelkan pada kayu lapis (teakwood) dan panel-panel mozaik yang menarik. 
Sebagaimana diketahui bahwa tingginya nilai jual kayu jati, pasar yang menjanjikan, teknik penanaman yang mudah, menimbulkan sangat tingginya animo rakyat terutama di hutan rakyat, baik di Jawa maupun luar Jawa. Semangat menanam yang tinggi ini harus dihargai, bahkan perlu terus didorong dan dibimbing agar menghasilkan tanaman yang berkualitas tinggi sebagaimana yang diharapkan. Saat ini sentuhan teknik silvikultur yang diberikan pada kegiatan hutan rakyat masih tertumpu pada tersedianya benih/semai seperti yang telah dilakukan secara tradisional.

Jenis jati di dunia terdapat empat spesies yaitu Tectona grandis, Tectona hamiltoniana, Tectona philippinensis dan Tectona abludens (Fauzi, 2005). Tectona grandis dikenal memiliki kualitas kayu yang paling baik dibandingkan dengan jenis lainnya. Usaha peningkatan kualitas benih di Propinsi Sulawesi Tenggara, khususnya di Kabupaten Muna terfokus pada T. grandis, karena nilai ekonominya yang sangat bagus. Di antara program pemuliaan tanaman jati di Sulawesi Tenggara, uji ras lahan menjadi perhatian. Diharapkan dari pengujian ini diperolah ras lahan terbaik untuk dikembangkan di Kabupaten Muna, walaupun pada saat ini telah lama dikembangkan tanaman jati di kabupaten tersebut.

Mempertimbangkan potensi sumber materi genetik yang semakin menurun dan sejalan dengan tingkat kerusakan hutan jati di Kabupaten Muna yang semakin tinggi dan keinginan yang kuat dari masyarakat maupun pemerintah di Propinsi Sulawesi Tenggara, maka sudah sangat mendesak dilakukan pengembangan yang lebih tertata dan terintegrasi, melalui kegiatan penanaman dengan menggunakan materi genetik yang lebih baik. Salah satu aspek penting yang perlu dilakukan adalah pembangunan sumber benih.

Uji ras lahan dilakukan karena adanya variasi geografik di dalam pohon hutan yang sifatnya turun temurun. Uji ras lahan diperlukan karena adanya masalah yang timbul di dalam penanaman pohon, terutama untuk jenis eksotik. Suatu jenis yang luas penyebarannya sering dijumpai adanya variasi. Variasi tersebut akan tampak pada morfologinya yang mempengaruhi cocok tidaknya ras tersebut tumbuh pada daerah tertentu.

Tujuan dari uji ras lahan adalah untuk mengetahui tren pertumbuhan pohon terhadap cuaca dan hubungannya dengan faktor-faktor lingkungan setempat dan juga untuk menyeleksi variasi genetik alamiah dan memiliki tipe pohon yang terbaik untuk penghutanan atau pemuliaan lebih lanjut (Wright, 1976). Dengan uji ras lahan diharapkan dapat diketahui asal sumber benih, dimana sumber benih tersebut telah beradaptasi dengan baik terhadap daerah pengembangannya serta dalam waktu dekat dapat memberikan hasil yang menguntungkan.

Menanam jenis pohon tanpa memperhatikan daerah asalnya, akan mengandung kemungkinan untuk menanam ras inferior. Sementara di tempat lainnya telah tersedia yang lebih baik. Apabila demikian halnya, akan diperoleh kerugian yang cukup besar akibat dari kesalahan pemilihan tempat asal atau ras lahannya.

\section{B. Tujuan}

a. Mengetahui persen hidup tanaman masing-masing ras lahan.

b. Mengetahui variasi pertumbuhan jati dari berbagai ras lahan.

c. Mengetahui ras lahan terbaik yang cocok untuk dikembangkan di Muna, Sulawesi Tenggara.

\section{BAHAN DAN METODE}

\section{A. Lokasi Penelitian}

Penelitian ini dilakukan di RPH Tampo, UPTD (Unit Pelaksana Tugas Daerah) Muna Utara I, Dinas Kehutanan Muna, Propinsi Sulawesi Tenggara. Suhu rata-rata tahunan $25^{\circ} \mathrm{C}$ sampai dengan $27^{\circ} \mathrm{C}$ dengan curah hujan per tahun rata-rata $1.800 \mathrm{~mm}$. Ketinggian tempat 5-10 $\mathrm{m}$ dpl dengan topografi tergolong datar dengan kelerengan 2-5\%. Tanahnya bertekstur lempung liat berpasir dengan $\mathrm{pH}$ 4,9 dan 
kandungan $\mathrm{N}$ total $0,06 \%, \mathrm{P}_{2} \mathrm{O}_{5} 8,72 \mathrm{ppm}$ dan $\mathrm{K}_{2} \mathrm{O} 0,31 \mathrm{me} / 100 \mathrm{~g}$. Drainase tanah agak lambat yaitu $0,62 \mathrm{~cm} /$ jam dengan kedalaman efektif perakaran $90-100 \mathrm{~cm}$.

\section{B. Bahan dan Alat Penelitian}

Bahan penelitian utama adalah tanaman uji ras lahan yaitu pertanaman jati umur 18 bulan yang benihnya berasal dari Ngliron (Jawa Timur), Padangan (Jawa Timur), dan lima ras lahan dari Muna, Sulawesi Tenggara yaitu : Tampo, Bonea, Raha, Matakidi dan Wakuru. Sedang bahan pembantu yang lain berupa pupuk organik, herbisida, insektisida dan bahan-bahan kimia.

Alat penelitian meliputi: mistar untuk mengukur tinggi tanaman, kaliper untuk mengukur diameter tanaman, $\mathrm{pH}$ meter untuk mengukur keasaman tanah, peta tanaman, blangko pengamatan, alat tulis menulis dan peralatan pertanian.

\section{Rancangan Penelitian}

Penelitian ini menggunakan Rancangan Acak Lengkap Berblok (RCBD), yang terdiri dari enam blok dan tujuh ras lahan. Setiap ras lahan dalam satu blok terdiri dari 25 tree plot (pohon pengamatan) yang ditanam bujur sangkar, dengan jarak tanam $3 \times 3 \mathrm{~m}$.

a. Tampo

Karakteristik ras lahan yang diujikan adalah sebagai berikut:

Suhu rata-rata tahunan $25^{\circ} \mathrm{C}$ sampai dengan $27^{\circ} \mathrm{C}$ dengan curah hujan per tahun rata-rata $1.800 \mathrm{~mm}$. Ketinggian tempat 5-10 m dpl dengan topografi tergolong datar dengan kelerengan 2-5\%. Tanahnya bertekstur lempung liat berpasir dengan $\mathrm{pH} 4,9$ dan kandungan $\mathrm{N}$ total $0,06 \%, \mathrm{P}_{2} \mathrm{O}_{5} 8,72 \mathrm{ppm}$ dan $\mathrm{K}_{2} \mathrm{O} 0,31 \mathrm{me} / 100 \mathrm{~g}$. Drainase tanah agak lambat yaitu $0,62 \mathrm{~cm} / \mathrm{jam}$ dengan kedalaman efektif perakaran $90-100 \mathrm{~cm}$.

b. Bonea

Suhu rata-rata tahunan $25^{\circ} \mathrm{C}$ sampai dengan $27^{\circ} \mathrm{C}$ dengan curah hujan per tahun rata-rata $1.800 \mathrm{~mm}$. Ketinggian tempat 10-15 m dpl dengan topografi tergolong datar dengan kelerengan 2-5\%. Tanahnya bertekstur lempung liat berpasir dan lempung berpasir dengan $\mathrm{pH}$ 6,7 dan kandungan $\mathrm{N}$ total $0,14 \%, \mathrm{P}_{2} \mathrm{O}_{5} 12,27 \mathrm{ppm}$ dan $\mathrm{K}_{2} \mathrm{O} 0,40 \mathrm{me} / 100 \mathrm{~g}$. Drainase tanah tergolong sedang, yaitu $4,92 \mathrm{~cm} /$ jam dengan kedalaman efektif perakaran $90-100 \mathrm{~cm}$.

c. Raha

Suhu rata-rata tahunan $25^{\circ} \mathrm{C}$ sampai dengan $27^{\circ} \mathrm{C}$ dengan curah hujan per tahun rata-rata $1.800 \mathrm{~mm}$. Ketinggian tempat 10-25 m dpl dengan topografi tergolong datar dengan kelerengan 2-5\%. Tanahnya bertekstur lempung liat berpasir dengan $\mathrm{pH} 5,4$ dan kandungan $\mathrm{N}$ total $0,10 \%, \mathrm{P}_{2} \mathrm{O}_{5}$ $6,0 \mathrm{ppm}$ dan $\mathrm{K}_{2} \mathrm{O} 0,16 \mathrm{me} / 100 \mathrm{~g}$. Drainase tanah tergolong agak lambat yaitu $0,51 \mathrm{~cm} / \mathrm{jam}$ dengan kedalaman efektif perakaran di atas $100 \mathrm{~cm}$.

d. Matakidi

Suhu rata-rata tahunan $25^{\circ} \mathrm{C}$ sampai dengan $27^{\circ} \mathrm{C}$ dengan curah hujan per tahun rata-rata $1.800 \mathrm{~mm}$. Ketinggian tempat 10-15 m dpl dengan topografi tergolong datar dengan kelerengan 0-2\%. Tanahnya bertekstur liat dan liat berpasir dengan $\mathrm{pH} 6,3$ dan kandungan $\mathrm{N}$ total $0,50 \%, \mathrm{P}_{2} \mathrm{O}_{5} 4,2$ ppm dan $\mathrm{K}_{2} \mathrm{O}$ $0,76 \mathrm{me} / 100 \mathrm{~g}$. Drainase tanah tergolong cepat yaitu $23,51 \mathrm{~cm} / \mathrm{jam}$ dengan kedalaman efektif perakaran $90-100 \mathrm{~cm}$.

e. Wakuru

Suhu rata-rata tahunan $25^{\circ} \mathrm{C}$ sampai dengan $27^{\circ} \mathrm{C}$ dengan curah hujan per tahun rata-rata $1.800 \mathrm{~mm}$. Ketinggian tempat 10-15 m dpl dengan topografi tergolong datar dengan kelerengan 0-1\%. Tanahnya bertekstur lempung berpasir dan lempung liat berpasir dengan $\mathrm{pH}$ 4,6 dan kandungan $\mathrm{N}$ total $0,06 \%, \mathrm{P}_{2} \mathrm{O}_{5} 13,07 \mathrm{ppm}$ dan $\mathrm{K}_{2} \mathrm{O} 0,22 \mathrm{me} / 100 \mathrm{~g}$. Drainase tanah tergolong cepat yaitu $39,13 \mathrm{~cm} /$ jam dengan kedalaman efektif perakaran $90-100 \mathrm{~cm}$. 


\section{f. Ngliron}

Suhu rata-rata tahunan $22^{\circ} \mathrm{C}$ sampai dengan $27^{\circ} \mathrm{C}$ dengan curah hujan per tahun rata-rata $1.170 \mathrm{~mm}$. Jenis tanah Grumusol dengan Bonita 4-4,5. Tanahnya bertekstur lempung liat berdebu dengan pH 6,52 dan kandungan $\mathrm{N}$ total $0,12 \%, \mathrm{P}_{2} \mathrm{O}_{5} 23,14$ ppm dan $\mathrm{K}_{2} \mathrm{O} 0,124$ me/ 100 g. Kedalaman efektif perakaran di atas $100 \mathrm{~cm}$.

g. Padangan

Suhu rata-rata tahunan $22^{\circ} \mathrm{C}$ sampai dengan $27^{\circ} \mathrm{C}$ dengan curah hujan per tahun rata-rata $1.900 \mathrm{~mm}$. Jenis tanah Latosol dengan Bonita 4. Tanahnya bertekstur liat dengan $\mathrm{pH}$ 6,78 dan kandungan $\mathrm{N}$ total $0,11 \%, \mathrm{P}_{2} \mathrm{O}_{5} 20,15 \mathrm{ppm}$ dan $\mathrm{K}_{2} \mathrm{O} 0,11 \mathrm{me} / 100 \mathrm{~g}$. Kedalaman efektif perakaran di atas $100 \mathrm{~cm}$.

\section{Parameter yang Diamati}

Parameter yang diamati pada penelitian ini adalah: persen hidup, pertumbuhan tinggi dan diameter tanaman.

\section{E. Analisis Data}

Analisis data hasil pengamatan dirata-rata, selanjutnya dianalisis menggunakan analisis varians dari rancangan acak lengkap berblok. Selanjutnya apabila terdapat perbedaan akan dilakukan uji lanjutan jarak Duncan (DMRT).

\section{F. Pelaksanaan Kegiatan}

a. Penanaman

Kegiatan ini diawali dengan pembabatan, penyemprotan herbisida, membagi areal penanaman menjadi 6 blok, pemasangan ajir, dan penggalian lubang tanam. Kegiatan penanaman dilakukan pada bulan Mei 2004. Materi tanaman berumur 4 bulan di persemaian dengan tinggi rata-rata $25 \mathrm{~cm}$.

b. Pembersihan gulma

Kegiatan ini dilakukan dengan pembabatan yang bertujuan untuk menghilangkan tanaman pengganggu yang dapat menjadi pesaing dalam mendapatkan unsur hara bagi tanaman pokok. Selain dibersihkan rumput-rumputnya, dilakukan juga pembersihan trubusan-trubusan liar yang tumbuh pada tonggak-tonggak jati. Setelah pembabatan kemudian dilakukan penyemprotan herbisida yang dicampur dengan perekat.

c. Pendangiran

Kegiatan ini bertujuan untuk memperbaiki airase tanah dengan cara menggemburkan tanah di sekitar tanaman pokok. Pendangiran dilakukan dengan mencangkul tanah dan membersihkan rumput beserta akar-akarnya di sekitar tanaman pokok berbentuk piringan berdiameter $60-80 \mathrm{~cm}$. Selain digemburkan, tanah di sekitar tanaman pokok juga ditinggikan dengan tujuan agar tidak tergenang di musim penghujan.

d. Pemupukan

Kegiatan ini dilaksanakan setelah kegiatan pendangiran. Pupuk yang digunakan adalah pupuk NPK dengan dosis $50 \mathrm{~g} /$ tanaman. Pemupukan dilakukan dengan membuat lubang pupuk sekeliling tanaman sedalam 5-10 cm dengan jarak $20 \mathrm{~cm}$ dari batang pokok. Setelah ditaburkan pupuk secara merata kemudian lubang ditutup dengan tanah.

e. Pemberantasan hama

Serangan hama yang sering terjadi adalah penggerek batang dan penggerek daun. Pemberantasan hama pengganggu dilakukan dengan menggunakan insektisida yang bersifat sistemik.

f. Pengukuran parameter tinggi dan diameter tanaman dilakukan setelah umur tanaman 18 bulan. 


\section{HASIL DAN PEMBAHASAN}

\section{A. Persen Hidup}

Persen hidup merupakan parameter untuk mengetahui kemampuan adaptasi suatu tanaman terhadap tempat tumbuh. Semakin besar nilai persen hidup tanaman, maka semakin tinggi tingkat kemampuan beradaptasi suatu ras lahan.

Hasil analisis varian persen hidup tanaman terhadap ras lahan tersaji pada Lampiran 1. Persen hidup dari 7 ras lahan cukup bervariasi. Tabel 1 menunjukkan ragam itu dengan hasil uji DMRTnya.

Tabel(Table) 1. Hasil uji DMRT persen hidup terhadap ras lahan jati pada umur 3 bulan dan 18 bulan (Result of DMRT test of survival rate on teak land race on 3 and 18 months old)

\begin{tabular}{|c|c|c|c|c|c|}
\hline \multirow{3}{*}{$\begin{array}{c}\text { Ras lahan } \\
\text { (Land race) } \\
\text { Wakuru }\end{array}$} & \multicolumn{5}{|c|}{ Persen hidup(Survival rate) (\%) } \\
\hline & \multicolumn{2}{|c|}{$\begin{array}{l}\text { Umur } 3 \text { bulan } \\
\text { ( } 3 \text { months old })\end{array}$} & \multicolumn{3}{|c|}{$\begin{array}{l}\text { Umur } 18 \text { bulan } \\
\text { (18 months old })\end{array}$} \\
\hline & 66,67 & $\mathrm{ab}$ & 49,33 & $\mathrm{a}$ & \\
\hline Padangan & 61,33 & $\mathrm{a}$ & 53,33 & $\mathrm{a}$ & $\mathrm{b}$ \\
\hline Matakidi & 77,33 & $\mathrm{abc}$ & 61,33 & $\mathrm{a}$ & $\mathrm{b}$ \\
\hline Ngliron & 80,00 & $\mathrm{abc}$ & 62,67 & $\mathrm{a}$ & $\mathrm{b}$ \\
\hline Raha & 80,00 & $\mathrm{abc}$ & 70,67 & $\mathrm{a}$ & $\mathrm{b}$ \\
\hline Bonea & 86,67 & $\mathrm{~b} \mathrm{c}$ & 77,33 & $\mathrm{a}$ & $\mathrm{b}$ \\
\hline Tampo & 90,67 & $\mathrm{c}$ & 82,67 & & $\mathrm{~b}$ \\
\hline
\end{tabular}

Rata-rata persen hidup pada umur 18 bulan mengalami penurunan bila dibandingkan persen hidup pada pengukuran umur 3 bulan. Penurunan ini menunjukkan masih terjadinya kematian tanaman sampai pada tahun pertama. Tabel 1 menunjukkan kemampuan adaptasi tanaman jati berbagai ras lahan bila ditanam di Tampo. Hasil ini menunjukkan bahwa ras lahan Tampo memiliki daya adaptabilitas tertinggi yaitu $82,67 \%$ karena ditanam pada kondisi lingkungan yang sama, sehingga secara genetik ras lahan Tampo akan lebih beradaptasi dengan lingkungannya. Hasil persen hidup terkecil diperoleh ras lahan Wakuru yaitu 49,33\%. Kemampuan adaptasi dari ras lahan yang letaknya berdekatan dengan Tampo yaitu Bonea (77,33 \%) dan Raha (70,67 \%) menunjukkan daya adaptabilitas yang tidak berbeda nyata dengan ras lahan Tampo dan berada di atas rata-rata persen hidup (65,3\%). Sedangkan ras lahan dari Ngliron (62,67 \%) dan Padangan (53,33 \%) mempunyai daya adaptabilitas di bawah nilai rata-rata. Wright (1976), Zobel dan Talbert (1984) menjelaskan bahwa pola adaptasi cenderung dipengaruhi oleh potensi genetik dan biasanya mempengaruhi satu tempat asal.

Persen hidup pada penelitian uji ras lahan ini lebih rendah apabila dibandingkan dengan persen hidup uji ras lahan tanaman jati di Kendari Selatan yang dilakukan oleh Santoso dkk. (2000) yang mencapai 94 - $98 \%$, dan ras lahan dari Nganjuk yang terendah (94\%) dan yang tertinggi berasal dari Tampo Kab. Muna (98\%).

\section{B. Tinggi Tanaman}

Hasil analisis varian pertumbuhan tinggi tanaman jati umur 18 bulan terhadap pengaruh ras lahan jati menunjukkan tidak berbeda nyata. Hasil analisis varian pertumbuhan tinggi tanaman tersaji pada Lampiran 2. Hasilnya menunjukkan bahwa tanaman jati pada umur 18 bulan belum menunjukkan adanya perbedaan pengaruh genetik yang bersumber pada ras lahan yang dapat mempengaruhi pertumbuhan 
tinggi tanaman. Hasil ini berbeda dengan penelitian yang dilakukan oleh Santoso dkk. (2000) di Kendari Selatan yang menunjukkan enam ras yang diuji, pada umur dua tahun pertumbuhan tingginya menunjukkan berbeda nyata. Ras lahan Petung (Nganjuk) menunjukkan pertumbuhan tertinggi yaitu $558,10 \mathrm{~cm}$. Sedang Restu dan Misto (2002) melaporkan pertumbuhan tinggi uji ras lahan jati di Wanagama Gunung Kidul umur 13 tahun menunjukkan perbedaan nyata.

Tinggi rata-rata tanaman uji ras lahan umur 18 bulan mencapai $102,35 \mathrm{~cm}$. Pertumbuhan tertinggi dicapai oleh ras lahan Bonea sebesar 118,23 cm dan tinggi tanaman terendah dicapai ras lahan Matakidi sebesar $88,93 \mathrm{~cm}$. Tinggi tanaman merupakan salah satu indikator kesuburan tapak pertanaman dan sering mengindikasikan status nutrisi tapak pertanaman (Zobel dan Talbert, 1984). Belum terjadinya variabilitas pertumbuhan tinggi dengan demikian mengindikasikan belum efektifnya ras lahan yang diuji dalam memanfaatkan status nutrisi yang tersedia pada tapak. Hasil pertumbuhan tinggi tanaman uji ras lahan tersaji pada Tabe12.

Tabel(Table) 2. Rata-rata tinggi tanaman uji ras lahan (Average of height growth on land race trial)

\begin{tabular}{|l|l|c|}
\hline No. & \multicolumn{1}{|c|}{$\begin{array}{c}\text { Ras lahan } \\
\text { (Land race) }\end{array}$} & $\begin{array}{c}\text { Tinggi(Height) } \\
(\mathrm{cm})\end{array}$ \\
\hline 1 & Matakidi & 88,93 \\
2 & Tampo & 98,49 \\
3 & Padangan & 100,95 \\
4 & Wakuru & 104,22 \\
5 & Raha & 104,89 \\
6 & Ngliron & 105,04 \\
7 & Bonea & 118,23 \\
\hline
\end{tabular}

Apabila ras lahan Tampo dijadikan sebagai pembanding, maka ada lima ras lahan yang pertumbuhan tingginya lebih baik yaitu ras lahan Padangan, Wakuru, Raha, Ngliron dan Bonea. Sedangkan apabila dilihat dari rata-rata pertumbuhan tinggi yaitu $102,35 \mathrm{~cm}$ maka tinggi tanaman ras lahan Wakuru, Raha, Ngliron dan Bonea berada di atas nilai rata-rata.

\section{Diameter Tanaman}

Hasil analisis varian diameter tanaman jati umur 18 bulan terhadap ras lahan menunjukkan perbedaan yang tidak nyata. Hasil penelitian ini berbeda dengan hasil penelitian yang dilakukan Santoso dkk. (2000) yang menyatakan pertumbuhan diameter uji ras lahan jati di Kendari Selatan umur 2 tahun berbeda nyata. Hasil analisis varian diameter tanaman uji ras lahan tersaji pada Lampiran 3. Rata-rata pertumbuhan diameter tanaman terbesar dicapai oleh ras lahan Bonea yaitu sebesar 20,08 $\mathrm{mm}$ dan diameter terkecil diperoleh ras lahan Matakidi yaitu sebesar $16,95 \mathrm{~mm}$. Rata-rata pertumbuhan diameter tanaman uji ras lahan umur 18 bulan tersaji padaTabel 3 .

Diameter rata-rata tanaman uji ras lahan adalah sebesar 18,09 mm. Ras lahan Tampo mempunyai diameter di bawah rata-rata diameter keseluruhan yaitu sebesar $18,03 \mathrm{~mm}$. Pertumbuhan diameter pada penelitian yang dilakukan oleh Santoso dkk. (2002) menunjukkan besarnya diameter tanaman jati umur 2 tahun mencapai 34,63 - 51,03 mm. Apabila ras lahan Tampo dijadikan pembanding maka ada tiga ras lahan yang mempunyai diameter di atas rata-rata yaitu Padangan $(18,26 \mathrm{~mm})$, Ngliron $(18,47 \mathrm{~mm})$ dan Bonea $(20,08 \mathrm{~mm})$. 
Tabel(Table) 3. Rata-rata diameter tanaman uji ras lahan (Average of diameter growth on land race trial)

\begin{tabular}{|c|l|c|}
\hline No. & \multicolumn{1}{|c|}{$\begin{array}{c}\text { Ras lahan } \\
\text { (Land race) }\end{array}$} & $\begin{array}{c}\text { Diameter (Diameter) } \\
(\mathrm{mm})\end{array}$ \\
\hline 1 & Matakidi & 16,95 \\
2 & Wakuru & 17,14 \\
3 & Raha & 17,66 \\
4 & Tampo & 18,03 \\
5 & Padangan & 18,26 \\
6 & Ngliron & 18,47 \\
7 & Bonea & 20,08 \\
\hline
\end{tabular}

\section{A. Rekomendasi Ras Lahan Terbaik Umur 18 Bulan}

Untuk menentukan ras terbaik dari tujuh ras lahan yang ditanam di lokasi uji ras lahan yang terletak di Tampo, Kab Muna, diasumsikan ras lahan Tampo dijadikan sebagai pembanding bagi ras lahan lain. Dengan asumsi tersebut, maka ras lahan Tampo dijadikan standar untuk perbandingan semua parameter yang meliputi persen hidup, tinggi dan diameter. Perbandingan nilai parameter pengamatan disajikan pada Tabel 4 .

Tabel (Table) 4. Perbandingan parameter pengamatan ras lahan (Comparison ofland race parameters)

\begin{tabular}{|c|c|c|c|c|c|c|c|c|}
\hline No & $\begin{array}{l}\text { Ras lahan } \\
\text { (Land race) }\end{array}$ & $\begin{array}{c}\text { Persen hidup } \\
\text { (Survival rate) } \\
(\%)\end{array}$ & $\begin{array}{c}\text { Perbandingan } \\
\% \text { hidup } \\
\text { (Comparison } \\
\text { of survival rate) } \\
(\%)\end{array}$ & $\begin{array}{l}\text { Tinggi } \\
\text { (Height) } \\
(\mathrm{cm})\end{array}$ & $\begin{array}{c}\text { Perbandingan } \\
\text { tinggi } \\
\text { (Comparison } \\
\text { of height) } \\
(\%)\end{array}$ & $\begin{array}{c}\text { Diameter } \\
\text { (Diameter) } \\
(\mathrm{mm})\end{array}$ & $\begin{array}{l}\text { Perbandingan } \\
\text { diameter } \\
\text { (Comparison of } \\
\text { diameter) } \\
(\%)\end{array}$ & $\begin{array}{c}\text { Jumlah } \\
\text { Perbandingan } \\
\text { (Sum of } \\
\text { comparison) } \\
\text { (\%) }\end{array}$ \\
\hline 1 & Bonea & 77,33 & 93,54 & 118,23 & 120,04 & 20,08 & 111,37 & 324,95 \\
\hline 2 & Tampo & 82,67 & 100,00 & 98,49 & 100,00 & 18,03 & 100,00 & 300,00 \\
\hline 3 & Raha & 70,67 & 85,48 & 104,89 & 106,50 & 17,66 & 97,95 & 289,93 \\
\hline 4 & Ngliron & 62,67 & 75,81 & 105,04 & 106,65 & 18,47 & 102,44 & 284,90 \\
\hline 5 & Padangan & 53,33 & 64,51 & 100,95 & 102,50 & 18,26 & 101,28 & 268,28 \\
\hline 6 & Wakuru & 49,33 & 59,67 & 104,22 & 105,82 & 17,14 & 95,06 & 260,55 \\
\hline 7 & Matakidi & 61,33 & 74,19 & 88,93 & 90,29 & 16,95 & 94,01 & 258,49 \\
\hline
\end{tabular}

Dengan pembandingan tiga parameter pengamatan dari tujuh ras lahan menggunakan ras lahan Tampo sebagai pembanding dapat diketahui ras lahan yang direkomendasikan di Tampo, Kabupaten Muna. Tabel 4 menunjukkan bahwa ras lahan Bonea menempati ranking pertama di atas Tampo dengan nilai lebih pada parameter tinggi dan diameter. Sementara Tampo menempati ranking kedua dengan nilai tertinggi pada parameter persen hidup yang menyatakan kemampuan beradaptasi. Hal ini sudah selayaknya karena penanaman dilakukan di lokasi Tampo, sehingga ras lahan Tampo mampu beradaptasi dengan keadaan lingkungannya. Ras lahan dari luar Muna yaitu Ngliron dan Padangan menempati ranking keempat dan kelima. Sedangkan ras lahan yang paling rendah tampilannya adalah ras lahan Matakidi. 


\section{KESIMPULAN}

1. Rata-rata persen hidup tanaman uji ras lahan umur 18 bulan adalah $65,3 \%$. Persen hidup rata-rata terbesar diperoleh ras lahan dari Tampo 82,67\%, sedangkan persen hidup terendah dihasilkan oleh ras lahan Wakuru yaitu sebesar $49,33 \%$.

2. Tinggi tanaman tertinggi dicapai oleh ras lahan dari Bonea yaitu sebesar $118,23 \mathrm{~cm}$, sedangkan yang terendah diperoleh dari ras lahan Matakidi yaitu $88,93 \mathrm{~cm}$.

3. Diameter rata-rata untuk semua ras lahan adalah $18,09 \mathrm{~mm}$. Diameter terbesar dicapai oleh Bonea yaitu sebesar 20,08 mm dan yang terkecil diperoleh ras lahan Matakidi yaitu sebesar 16,95 mm.

4. Pada umur tanaman uji 18 bulan, tanaman dari ras lahan Bonea menunjukkan pertumbuhan yang terbaik.

\section{DAFTAR PUSTAKA}

Anonim. 2002. Informasi Singkat Benih. Direktorat Perbenihan Hutan Indonesia, Indonesian Forest Seed Project, Danida Forest Seed Centre.

Direktorat Perbenihan Tanaman Hutan. 2002. Pedoman Sertifikasi Mutu Fisik-Fisiologis Benih, Jakarta.

Mahfudz. 2002. Diskusi Penyediaan Bibit Unggul Jati. Prosiding Pusat Penelitian dan Pengembangan Bioteknologi dan Pemuliaan Tanaman Hutan, Yogyakarta.

Poerwokoesoemo, R.S. 1956. Jati Jawa (Tectona grandis L.f), Bogor

Restu, M. dan Misto. 2002. Variasi Genetik Pertumbuhan Tanaman Jati (Tectona grandis L.f) Uji Provenansi di WanagamaYogyakarta. Buletin Penelitian Kehutanan. Balai Penelitian Kehutanan Ujung Pandang Vol. 8 No. 2 Tahun 2002.

Santoso, B., Misto, M. Yusril dan M.A. Rakman. 2000. Pertumbuhan Tanaman Jati dari berbagai Ras Lahan di Kendari Selatan. Balai Penelitian dan Pengembangan Kehutanan Sulawesi, Makassar.

Santoso, B. 2003. Uji Coba Peningkatan Kualitas Benih dan Bibit Jati Muna. Balai Penelitian dan Pengembangan Kehutanan Sulawesi, Makassar.

Sarjuningtyas, S. 1994. Studi Awal Variasi Genetik Sumber Benih Jati (Tectona grandis L.f) dari wilayah Perum Perhutani Unit I Jawa Tengah. Tesis Pasca Sarjana (Tidak Dipublikasikan)

Soerianegara, I. 1970. Pemuliaan Hutan. Laporan No. 104. Lembaga Penelitian Hutan, Bogor.

Soeseno, O. H., B.H. Eko, Suhardi dan M. Na'iem. 1992. Status Pemuliaan Pohon dan Bioteknologi Hutan di Indonesia Saat Ini. Prosiding Seminar Nasional Status Silvikultur di Indonesia Saat ini. Wanagama, Gunung Kidul, Yogyakarta.

Wright, J.W. 1976. Introduction to Forest Genetics. Academic Press, New York, San Fransisco, London.

Zobel, B. and J. Talbert. 1984. Applied Forest Tree Improvement. John Willey and Sons, New York, Chichester, Brisbane, Toronto, Singapore. 
Lampiran(Appendix) 1. Analisis varian persen hidup tanaman uji ras lahan (Analysis of variance of survival rate on land race trial)

\begin{tabular}{|l|c|c|c|c|}
\hline $\begin{array}{c}\text { Sumber Variasi } \\
\text { (Source of variation) }\end{array}$ & $\begin{array}{c}\mathrm{Db} \\
(d f)\end{array}$ & $\begin{array}{c}\text { Jumlah Kuadrat } \\
\text { (Sum of squares) }\end{array}$ & $\begin{array}{c}\text { Kuadrat Tengah } \\
\text { (Mean square) }\end{array}$ & F hit \\
\hline Ras lahan & 6 & 1028,22 & 171,370 & $3,273^{*}$ \\
Galat & 14 & 733,05 & 52,361 & \\
\hline Total & 20 & 1761,27 & & \\
\hline
\end{tabular}

Lampiran(Appendix) 2. Analisis varian pertumbuhan tinggi tanaman uji ras lahan (Analysis of variance of height growth on land race trial)

\begin{tabular}{|c|c|c|c|c|}
\hline $\begin{array}{c}\text { Sumber Variasi } \\
\text { (Source of variation) }\end{array}$ & $\begin{array}{c}\mathrm{Db} \\
(d f)\end{array}$ & $\begin{array}{c}\text { Jumlah Kuadrat } \\
\text { (Sum of squares) }\end{array}$ & $\begin{array}{c}\text { Kuadrat Tengah } \\
\text { (Mean square) }\end{array}$ & F hit \\
\hline Blok & 5 & 7705,396 & 1541,079 & $2,813^{*}$ \\
Ras lahan & 6 & 2781,182 & 463,530 & $0,846^{\text {ns }}$ \\
Galat & 30 & 16434,361 & 547,812 & \\
\hline Total & 41 & 26920,940 & & \\
\hline
\end{tabular}

Lampiran (Appendix) 3. Analisis varian diameter tanaman uji ras lahan (Analysis of variance of diameter growth on land race trial)

\begin{tabular}{|l|c|c|c|c|}
\hline $\begin{array}{c}\text { Sumber Variasi } \\
\text { (Source of variation })\end{array}$ & $\begin{array}{c}\mathrm{Db} \\
(d f)\end{array}$ & $\begin{array}{c}\text { Jumlah Kuadrat } \\
\text { (Sum of squares) }\end{array}$ & $\begin{array}{c}\text { Kuadrat Tengah } \\
\text { (Mean square) }\end{array}$ & F hit \\
\hline Blok & 5 & 54,333 & 10,867 & 1.133 \\
Ras lahan & 6 & 38,987 & 6,492 & $0.677^{\mathrm{ns}}$ \\
Galat & 30 & 287,753 & 9,592 & \\
\hline Total & 41 & 381,073 & & \\
\hline
\end{tabular}

